\title{
The Present and Possible Future of Quantitative Criminology
}

\author{
David McDowall
}

Published online: 22 September 2010

(C) Springer Science+Business Media, LLC 2010

By the time I became editor of $J Q C$, it was already a thriving and well-regarded journal. Jamie Fox, John Laub, and Mike Maltz had done the hard work necessary to develop a niche for it within criminology, and to make its presence known to potential contributors. Due to their efforts, it had built up a solid base of readers and had earned a reputation for publishing high-quality scholarship. The editor did not have to worry about finding enough papers to fill issues, and so did not have to think much about the state of quantitative criminology in general. As with other established journals, the major editorial task was to oversee the selection of manuscripts from a pool of mostly sound and innovative submissions.

These were very fortunate circumstances for me, and they reflected the significant progress that the field and the journal had made. They nevertheless provided no insights into the development of quantitative criminology, nor any illuminating stories about the role that $J Q C$ had played in it. I therefore have nothing original to say about these matters, and I will not try to disguise the fact by reflecting on them.

I appreciate, however, the opportunity that the editors have given me to comment on the present state and possible future direction of quantitative criminological research. The remaining sections of this essay will first review the current situation, and will then consider what the field needs and where it may be headed.

\section{Quantitative Criminology's Present State}

Considerable evidence supports the view that quantitative criminology is currently at a high point. Statistically sophisticated studies regularly appear in all of the field's major journals, and authors take pride in the quality of their analytical efforts. Truly bad statistical practice is correspondingly less frequent than it was even a decade ago, and readers and reviewers are less likely to tolerate it. The field has always had a substantial number of

D. McDowall ( $\square)$

School of Criminal Justice, University at Albany-SUNY, Albany, NY 12222, USA

e-mail: mcdowall@albany.edu 
scholars who seriously attended to methodological issues, but that group is now noticeably larger.

If job applicants at Albany's School of Criminal Justice are representative, recent $\mathrm{PhD}$ 's more often list quantitative methods among their areas of competence than was true in the past. Entering graduate students are more likely to express a desire to learn about methodology, and the general quality of quantitative training is better. At the higher end of performance, the variety and quality of the articles in $J Q C$ also attest to the popularity of methodological topics.

Editors and reviewers at other journals do still sometimes dismiss articles with unfamiliar methodologies as "too statistical," and-regardless of their substantive merits-recommend that authors submit them to $J Q C$ instead. Some criminologists also continue the anti-intellectual practice of rejecting quantitative methods entirely. As at the time of its founding, $J Q C$ exists in part to counter biases against quantitative work, and it is the field's only home for analytically esoteric studies. The threshold for "too statistical" seems higher than it once was, however, and criminologists overall appear more open to new approaches than was perhaps true in the past. At a minimum, authors rarely have to apologize for complex analyses.

In addition, researchers more frequently select statistical models to fit their substantive questions, and they are less likely to treat statistics as rituals or magic spells. This is not universally true, of course, and some papers remain little more than hodgepodges of Stata printouts and misused econometric buzzwords. Analysts also still sometimes contrive research questions solely to apply a fashionable methodology, such as negative binomial regression or multilevel analysis. Yet this is true in any field, and the range of methods in $J Q C$ articles match the diversity of the research questions that their authors address.

Earlier in its history, the journal published papers whose main point was to illustrate a technique or model developed in another field. The major claim of these articles was simply that no one had previously applied the method to criminological data, and the relevance of the example was almost beside the point. Such contributions are now rare, and instead authors concentrate on the substantive value of the findings that a new method produces.

$J Q C$ has clearly been influential in bringing about this turn of events. The journal provides a place for undertaking discussions that would not easily fit elsewhere, and so would be less likely to occur at all. The applied articles that it publishes help raise standards for acceptable work, ultimately influencing statistical practice in the field more broadly. Without $J Q C$, progress in quantitative criminology would still occur, but it would be slower and less steady.

\section{Possible Future Directions}

No reason exists to doubt that quantitative criminology will continue to grow and develop in the future. Yet it also seems likely that quantitative work will move in some new directions as it evolves. The following sections consider two possible avenues for change, both of which address current limitations of the field.

More Methodological Development

First, criminology lags in the development of original methods, and it would be stronger if it had its own methodological specialists. Other social science fields have subareas that 
focus on techniques specific to their substantive interests. The most obvious of these are the "metrics" in economics and psychology, but sociology and political science also have their quantitative branches. Despite the widespread use of sophisticated methods, the absence of an area devoted to methodological innovation leaves criminology in a comparatively disadvantaged position.

Of course, to some degree criminologists do currently engage in methodological development. $J Q C$ plays much the same role as do the quantitative journals in other fields, and it has published many articles that propose new techniques and approaches. As the journal's editor, I especially tried to encourage such submissions, and to insure that they received careful evaluations from knowledgeable reviewers. I am certain that this was also true for my predecessors and is true for the current editors. Still, the number of high-quality manuscripts that focus on new methods is not sufficient to fill the journal's pages. JQC publishes as many substantively-oriented articles as it does partly due to the scarcity of thoroughly methodological contributions.

The lack of focus on developing new methods in part reflects the position of criminology as a synthesizing field that spans several distinct disciplines. Criminologists can borrow from technical research in these disciplines, and they can publish their own methodological studies within them. For the most part, criminologists do not have a strong incentive to invent analytical methods because they can easily obtain what they need elsewhere.

Yet criminology is the source of many rich and interesting data sets, and writers in other disciplines often use them to illustrate their own methodological innovations. Future criminologists will probably more often extend existing techniques themselves, and also devise new approaches that better suit the field's topical concerns. Trajectory models for longitudinal analysis already have a strong connection to criminology (e.g., Land and Nagin 1996; Nagin 2005), and the same is true for some multilevel models (e.g., Raudenbush et al. 2003). Many additional opportunities for innovation exist, however, involving problems in spatial statistics, missing data imputation, and other areas. In survey research, for example, criminologists have a natural interest in estimation methods for limited populations (e.g., institutionalized persons), rare outcomes (e.g., defensive firearm use), and small areas (e.g., blocks).

Technical advances often come from efforts to address applied issues, and knowledge of theoretical and empirical concerns is important for methodological research more generally. Although criminologists can benefit from developments in other fields, the purpose of this work was not to answer questions of interest to them. Substantive understanding of crime could progress more rapidly if criminology had its own group methodological specialists.

If original methodological research does become more common, it will likely occur as general levels of quantitative training rise. These increases will create a larger audience for such contributions, and universities will be more likely to hire scholars who can make them. Due to its interest in methodology for its own sake, $J Q C$ should be important in facilitating this process.

\section{More Attention to Data Issues}

Besides greater concern with methodological innovation, a second change beneficial to quantitative criminology would be increased attention to the unique characteristics of crime-related variables. The issues involved here have much in common with devising new methods, but they are distinct enough that they merit separate attention. Partly because they 

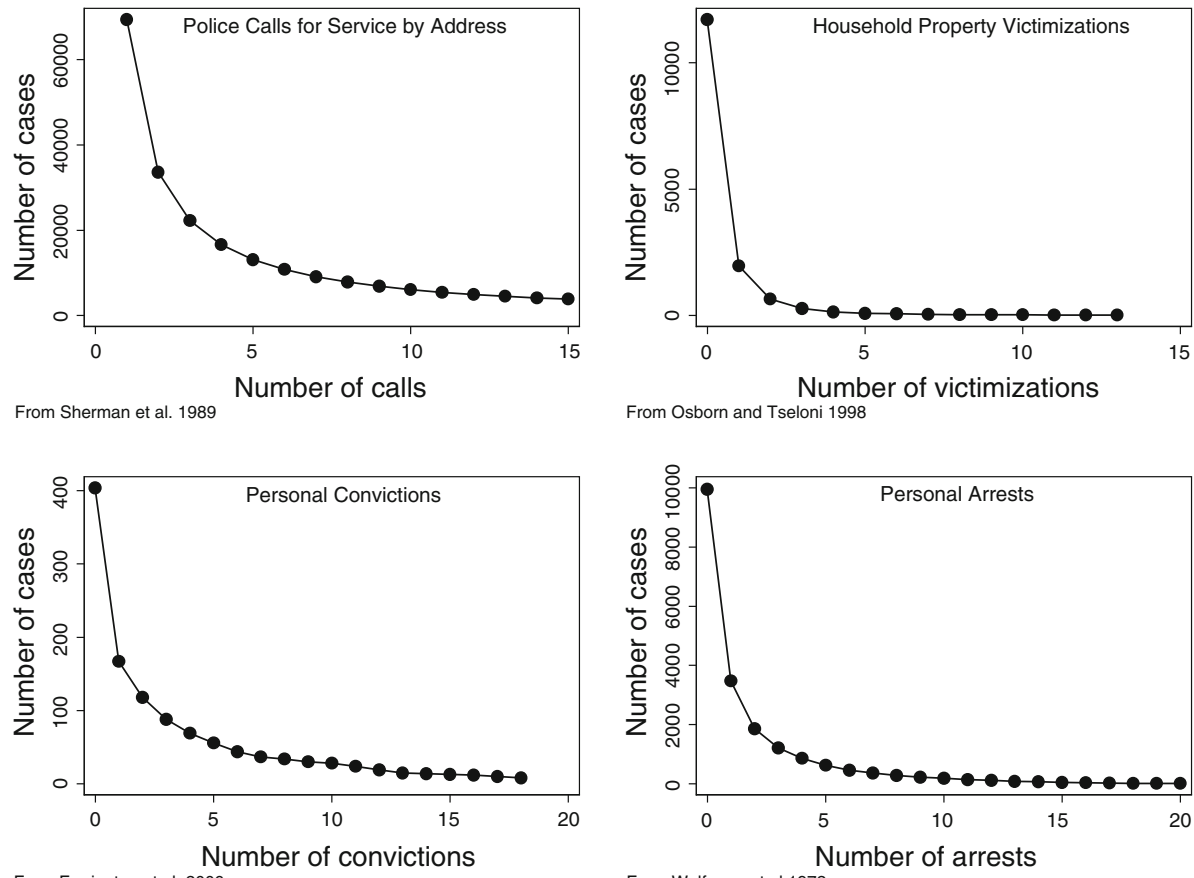

Fig. 1 Cumulative frequency distributions for four variables

rely so heavily on approaches from other fields, criminologists sometimes overlook important features of their own data.

An illustration of how researchers neglect useful information comes from the skewed distributions of many variables related to offending and victimization. Figure 1 presents cumulative frequency distributions for four representative cases: calls for police service (Sherman et al. 1989), household property victimizations (Osborne and Tseloni 1998), individual criminal convictions (Farrington et al. 2006) and individual arrests (Wolfgang et al. 1972). The general shapes of these distributions also appear for other individual-level outcomes, and they hold across all major sources of data, including self-reports, official records, and victim surveys.

Criminologists generally regard the asymmetrical distributions as nuisances or worse. Following the practice of other social scientists, their goal has been to estimate regression equations for the conditional means of the variables, and the skews complicate their efforts. In part due to cautions and examples that have appeared in $J Q C$, simply ignoring asymmetry has become increasingly unacceptable. The usual solutions have been either to adjust the data in order to remove the skews, or to revise models in order to control for them. Specific approaches have included logarithmic and other variable transformations (Nelson 1981), negative binomial regression (Osgood 2000), censored regression (Osgood et al. 2002; Sullivan et al. 2008), and nonparametric regression (Britt 2009).

To varying degrees, these models and transformations have been helpful in improving estimates of the conditional means. No approach has seriously considered the source of the skews, however, or made their properties objects of study in themselves. The existing 

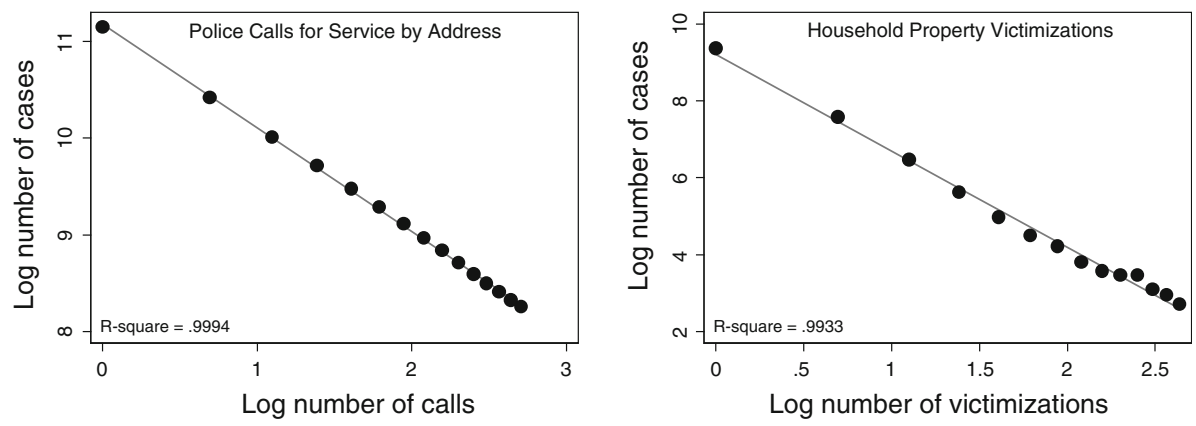

From Sherman et al. 1989

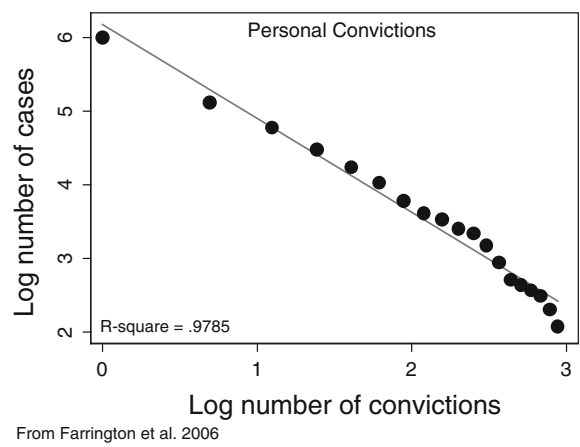

From Osborn and Tseloni1998

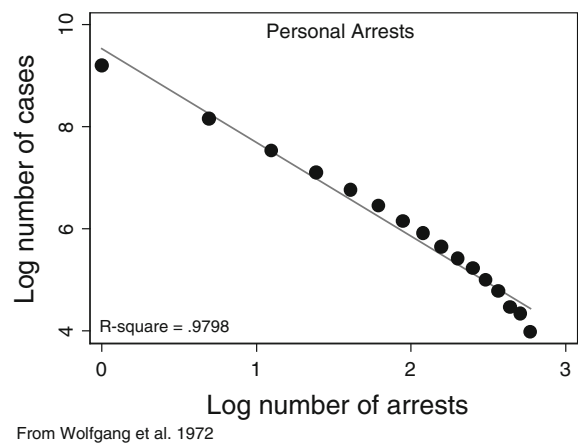

Fig. 2 Cumulative frequency distributions for four variables, $\log -\log$ scale

methods mold the data to meet model requirements, and researchers choose them as a matter of convenience. Yet asymmetry is ubiquitous in criminology, and avoiding it amounts to disregarding an obvious fact.

Figure 2 displays the same distributions as in Fig. 1, but on $\log -\log$ scales and with superimposed regression lines. ${ }^{1}$ Possibly excepting the arrest and conviction data, the lines closely fit each variable, implying a proportional relationship between the size and frequency of the outcomes. These relationships are similar to the power laws proposed by Zipf, Pareto, and others and they appear widely in nature (Newman 2005). Power law relationships have been the subject of much research in the natural sciences, and they are a staple topic in popular presentations of "complexity theory" (e.g., Ball 2004). Interesting by themselves, the skews in crime-related variables might therefore conceivably link criminology to other fields.

Figure 2 is not enough to show that power laws actually exist in criminological data. Among other limitations, the distributions cover narrow ranges of values; the number of service calls, for example, varies only between one and fifteen. Power laws can provide misleading fits to limited spans, and physical applications usually consider ranges of one to one thousand or more. Least squares also has deficiencies in modeling power laws (Newman 2005), and the arrest and conviction data deviate from a line in the upper tail.

\footnotetext{
${ }^{1}$ Except for the Sherman et al. data, these plots add one to the counts to avoid dropping the zero categories.
} 
Other skewed distributions might ultimately provide a better characterization of these variables (see, e.g., Kleiber and Kotz 2003). ${ }^{2}$

The relationships in Fig. 2 do nevertheless point to the desirability of further studying the asymmetry in criminological outcomes. More generally, they suggest that criminologists might make significant advancements if they closely considered the nature of their data. Other features of crime variables, such as their characteristic trends and temporal patterns (see, e.g., McDowall 2002; McDowall and Loftin 2005, 2009), could also be useful for developing theories and empirical generalizations. Through these efforts, criminology might eventually come to contribute to the fields from which it now draws.

Although it could have important consequences, devoting more attention to the unique features of criminological data would not require a fundamental change in current practice. This makes it realistic to imagine that it might occur in the not-distant future. As criminology continues to develop, researchers will naturally search for new topics to study, and the singular characteristics of the data are apparent enough to make them an obvious choice. JQC should again be important in fostering this type of work, because its necessarily quantitative nature might initially make it unappealing to other journals.

\section{Conclusions}

Quantitative methods and research have a prominent position within the field of criminology. Quantitative studies are presently numerous and of generally high quality, and $J Q C$ has been a major force in influencing this outcome. The current essay has presented two not-particularly-daring predictions about where research might progress in the future, and has argued that these changes could be of substantial benefit. The accuracy of such forecasts is open to doubt, and the future may look nothing like the essay has imagined it. It seems certain, however, that quantitative criminology will continue to grow and improve in quality over the next twenty-five years, just as it has over the last twenty-five. It also seems certain that $J Q C$ will continue to be in the forefront of these developments.

\section{References}

Ball P (2004) Critical mass: How one thing leads to another. Farrar, Straus and Giroux, New York

Britt CL (2009) Modeling the distribution of sentence length decisions under a guidelines system: An application of quantile regression models. J Quant Criminol 25:341-370

Farrington DP, Cold JW, Harnett LM, Jolliffe D, Soteriou N, Turner RE, West DJ (2006) Criminal careers up to age 50 and life success up to age 48: New findings from the Cambridge study in delinquent development. (Home Office Research Study 299). Home Office, Development and Statistics Directorate, London

Kleiber C, Kotz S (2003) Statistical size distributions in economics and actuarial sciences. Wiley, New York

Land KC, Nagin DS (1996) Micro-models of criminal careers: A synthesis of the criminal careers and life course approaches via semiparametric mixed poisson regression models, with empirical applications. J Quant Criminol 12:163-191

McDowall D (2002) Tests of nonlinear dynamics in US homicide time series, and their implications. Criminology 40:711-736

McDowall D, Loftin C (2005) Are US crime rate trends historically contingent? J Res Crime Delinq 42:359-383

\footnotetext{
${ }^{2}$ In addition, the apparent power law distributions apply only to individual-level phenomena. Aggregate variables also tend to be skewed, but with a form different from that in the individual case.
} 
McDowall D, Loftin C (2009) Do US city crime rates follow a national trend? The influence of nationwide conditions on local crime patterns. J Quant Criminol 25:307-324

Nagin DS (2005) Group-based modeling of development. Harvard University Press, Cambridge, MA

Nelson JF (1981) Choosing and interpreting a metric for data analysis. Evaluation Review 5:639-670

Newman MEJ (2005) Power laws, pareto distributions and Zipf's law. Contemp Phys 46:323-351

Osborne D, Tseloni A (1998) The distribution of household property crimes. J Quant Criminol 14:307-330

Osgood DW (2000) Poisson-based regression analysis of aggregate crime rates. J Quant Criminol 16:21-43

Osgood DW, Finken L, McMorris BJ (2002) Analyzing multiple-item measures of crime and deviance II: Tobit regression analysis of transformed scores. J Quant Criminol 18:319-347

Raudenbush S, Johnson C, Sampson RJ (2003) A multivariate, multilevel Rasch model with application to self-reported criminal behavior. Sociol Methodol 33:169-211

Sherman LS, Gartin PR, Buerger ME (1989) Hotspots of predatory crime: Routine activities and the criminology of place. Criminology 27:27-55

Sullivan CJ, McGloin JM, Piquero AR (2008) Treating the deviant Y* in criminology: An examination of the assumptions of censored normal regression and some potential alternatives. J Quant Criminol 24:399-421

Wolfgang ME, Figlio RM, Sellin T (1972) Delinquency in a birth cohort. University of Chicago Press, Chicago 